\title{
Contrast-Enhanced Subharmonic Ultrasound Imaging
}

National Cancer Institute

\section{Source}

National Cancer Institute. Contrast-Enhanced Subharmonic Ultrasound Imaging. NCI

Thesaurus. Code C133723.

A variation of contrast-enhanced ultrasound imaging that centers the receiving bandwidth at half the transmitting frequency in order to suppress tissue signals during vascular imaging studies. 